\title{
O ESTÁGIO DE CONVIVÊNCIA EM CASOS DE ADOÇÃO: UMA COMPREENSÃO FENOMENOLÓGICA
}

\author{
The Stage of Coexistence in Cases of Adoption: a phenomenological understanding \\ La Etapa de Convivencia en Casos de Adopción: una comprensión fenomenológica
}

Laura Cristina Santos Damásio de Oliveira Ana AndrÉa Barbosa Maux

\begin{abstract}
Resumo: Este artigo teórico possui como temática o estágio de convivência em casos de adoção, etapa obrigatória em lei na qual crianças aptas para adoção passam a conviver com candidatos habilitados para tal, visando discutir a filiação adotiva e como ela pode ocorrer nesse período. Legalmente, esse momento deve ser acompanhado por equipe psicossocial, sendo emitido parecer técnico sobre o caso. Mas, o que acontece nesse processo? O que deverá ser observado? Uma revisão bibliográfica em três Bancos de Dados concluiu que as produções sobre a temática são insipientes, especialmente do ponto de vista da Fenomenologia. Durante o estágio de convivência, é comum que os pretendentes a pais tentem agradar a criança ou temam sua história, bem como esta pode tentar agradar ou testar os limites. Acompanhar esse período e discutir essas questões possibilita que todos habitem esse lar e essas relações, contribuindo para maior segurança na concretização da adoção.
\end{abstract}

Palavras-chave: Adoção; Fenomenologia; Filiação; Processos Legais.

\begin{abstract}
This theoretical article has as its theme the stage of cohabitation in cases of adoption, a mandatory step in law in which children suitable for adoption pass to live with qualified candidates. It aimed to discuss adoptive filiation and how it occurs in the stage of cohabitation. Legally, this moment must be accompanied by psychosocial team that delivers technical opinion about it. But what happens in this process? What should be observed? A bibliographical review in three Databases concluded that productions on the subject are insipient, especially from the point of view of the Phenomenology. During the cohabitation stage, it's common for parents to try to please the child, or to fear their history, as well as the child try to please or to test limits. Following this period and discussing these issues enables everyone to inhabit this home and these relationships, contributing to greater security in the adoption implementation.
\end{abstract}

Keywords: Adoption; Phenomenology; Affiliation; Legal Processes.

Resumen: Este artículo teórico posee como temática la etapa de convivencia en casos de adopción, etapa obligatoria en ley en la que niños aptos para la adopción pasan a convivir con candidatos habilitados para tal, buscando discutir la afiliación adoptiva y cómo puede ocurrir en ese período. Legalmente, ese momento debe ser acompañado por equipo psicosocial, siendo emitido dictamen técnico sobre el caso. Pero, ¿qué sucede en este proceso? ¿Qué debe observarse? Una revisión bibliográfica en tres Bases de datos concluyó que las producciones sobre la temática son insípidas, especialmente desde el punto de vista de la Fenomenología. Durante la etapa de convivencia, es común que los pretendientes a padres traten de agradar al niño o teman su historia, así como ésta puede tratar de agradar o probar los límites. Acompañar ese período y discutir esas cuestiones posibilita que todos habite ese hogar y esas relaciones, contribuyendo para mayor seguridad en la concreción de la adopción.

Palabras clave: Adopción; Fenomenología; Afiliación; Procesos Legales.

\section{Introdução}

O presente artigo parte da experiência das autoras em uma Vara da Infância e Juventude, no acompanhamento dos casos de adoção. A partir de uma reflexão embasada na fenomenologia hermenêutica de Martin Heidegger, o artigo busca discutir a importância do estágio de convivência para a concretização da adoção, trazendo apontamentos sobre a construção do vínculo adotivo que se inicia nesse período.

Antes de prosseguir, é preciso definir o estágio de convivência. A adoção no Brasil atualmente é regida pelo Estatuto da Criança e do Adolescente (ECA), de 1990, que estabelece, em seu artigo 19, que "toda criança e adolescente tem direito a ser criado e educado no seio de sua família e excepcionalmente, em família substituta (...)”. Em casos de destituição do Poder Familiar, esse público torna-se apta para adoção, sendo tutelada pelo Estado, podendo ser colocado em outra família.

Quando isso acontece, é verificado o cadastro dos pretendentes a pais adotivos, previamente inscritos nas Varas de Infância e Juventude (VIJ), e caso haja criança ou adolescente compatível com o perfil desejado pelos pretendentes, entra-se em 
contato com estes e, após confirmarem o interesse em conhecer a criança ${ }^{1}$, ocorre os primeiros contatos entre eles. Tendo ambos demonstrado interesse em dar prosseguimento ao processo, inicia-se o estágio de convivência, período no qual a criança passa a residir na casa do candidato. E durante um período determinado pela autoridade judiciária, a família será acompanhada pela equipe técnica da VIJ. Busca-se verificar se nessa nova família a criança terá garantido seu direito à convivência familiar saudável. Tal acompanhamento é seguido de um relatório técnico, onde constará a opinião sobre a adaptação da nova configuração parental, bem como as mudanças acontecidas após a chegada de mais um membro no núcleo familiar.

A partir do relatório, uma das três situações acontecerá: a primeira é a constatação de que a adoção é possível acontecer adequadamente e, nesse caso, ela prossegue até sua conclusão definitiva. Mas também pode ser verificado que a criança não está tendo seus direitos respeitados e, portanto, a sugestão é pela retirada do seio dessa família para ser encaminhada para outra cadastrada. Ou, pode haver desistência do processo por parte dos pretendentes, que podem não se adaptar às mudanças ou à criança, devolvendo a mesma à tutela do Estado.

Ou seja, o estágio de convivência é o período em que a criança passa a conviver com os pretendentes à adoção "para se conhecerem e sentirem a possibilidade de uma aproximação satisfatória para ambos" (Souza \& Casanova, 2011).

O ECA inicialmente trazia que o estágio de convivência poderia ser dispensado no caso de comprovação do vínculo entre adotando e adotado, independente da idade da criança, ou no caso de menores de um ano de idade. Portanto, ter a criança sob sua guarda de fato já era suficiente para dispensar o estágio de convivência. Para adoção internacional, se o adotado fosse menor de dois anos de idade, o estágio era fixado em, no mínimo, 15 dias, ou 30 dias nas situações em que as crianças fossem maiores do que essa idade.

Em 2009, a Lei 12.010, também conhecida como Nova Lei da Adoção, trouxe algumas alterações. A partir dela, o estágio de convivência é obrigatório, independente da idade da criança, embora não estabeleça o tempo mínimo, deixando a cargo do magistrado, salvo em casos de adoção internacional, que tem prazo mínimo de um mês. Só poderá ser dispensado em casos de existência de guarda legal anterior. Além disso, a lei assegura que o estágio de convivência deve ser acompanhado por equipe interprofissional, sendo este um ponto crítico e de

\footnotetext{
1 A partir daqui, ao utilizarmos o termo "criança", nos referimos tanto à adoção de crianças quanto de adolescentes, pois, o número de adoção de crianças é maior. De acordo com o Conselho Nacional de Justiça (CNJ, 2019), o número de pretendentes que aceitam adotantes a partir dos 12 anos varia de $0.71 \%$ a $0.16 \%$. Assim, adotamos o termo "criança" no decorrer do nosso estudo.
}

grande valia, pois o relatório psicossocial elaborado é levado em consideração na decisão de concessão da adoção. Os parágrafos $1^{\circ}, 2^{\circ}, 3^{\circ}$ e $4^{\circ}$ do artigo 46 (Lei 12.010, 2009), apresentam que:

§ 1ํo O estágio de convivência poderá ser dispensado se o adotando já estiver sob a tutela ou guarda legal do adotante durante tempo suficiente para que seja possível avaliar a conveniência da constituição do vínculo.

$\S 2^{\circ}$ A simples guarda de fato não autoriza, por si só, a dispensa da realização do estágio de convivência.

$\S 3^{\text {o }}$ Em caso de adoção por pessoa ou casal residente ou domiciliado fora do País, o estágio de convivência, cumprido no território nacional, será de, no mínimo, 30 (trinta) dias.

$\S \quad 4^{\circ} \quad \mathrm{O}$ estágio de convivência será acompanhado pela equipe interprofissional a serviço da Justiça da Infância e da Juventude, preferencialmente com apoio dos técnicos responsáveis pela execução da política de garantia do direito à convivência familiar, que apresentarão relatório minucioso acerca da conveniência do deferimento da medida.

Mais adiante, sobre adoção internacional, no artigo $52 \S 8^{\circ}$ traz que o adotante só pode sair do Brasil após a ação de adoção transitar em julgado. Logo, entende-se que o estágio de convivência deve ser realizado em território nacional e acompanhado pela equipe da Vara da Infância e Juventude da comarca na qual a criança se encontra.

Dessa forma, esse período de convivência é delicado, e envolve adaptação tanto dos adotantes quanto da criança. E por conta dessa delicadeza é importante que seja acompanhado por profissionais que estejam à disposição, tanto para avaliar o momento, quanto para esclarecer dúvidas e fazer orientações. Assim, o estágio de convivência, em sua operacionalização, é um momento no qual os profissionais devem estar atentos à formação de vínculo entre os envolvidos na adoção, mas também em acolher possíveis angústias e dificuldades suscitadas durante esse momento.

Mas o que seria, de fato, esse período de construção de vínculo? Em quanto tempo pode-se mensurar uma relação? E, em razão dos vários fatores que possam interferir no estágio de convivência como a história pregressa da criança, o preparo dos pretendentes a pais, a disponibilidade afetiva de ambos - como os profissionais das Varas podem acompanhar e ajudar nesse momento? Especialmente se pensarmos sobre adoções tardias, quando a criança tem idade superior a dois anos de idade e que são perpassadas por mais mitos e fantasias (Bicca \& Grzybowski, 2014), o estágio de convivência surge não só como uma etapa a ser cumprida devido à lei, mas como um passo importante na construção de 
vínculos, já que envolve o início de reorganização familiar, desenvolvimento de novos papéis e criação de nova rotina (Segalin, 2013).

Além disso, entende-se que a construção de vínculo tem um tempo subjetivo, diferente para cada pessoa envolvida. Mas, no acompanhamento do estágio de convivência, a equipe interprofissional deve elaborar um relatório apontando os aspectos favoráveis ou não para a adoção. Nesse sentido, é preciso pensar o trabalho dessa equipe no acompanhamento de algo perpassado por emoções e tempo psicológico individual dos envolvidos, dentro de um contexto que se baseia no tempo jurídico. Questões como essa perpassam esse estudo e esse artigo pode auxiliar o trabalho dos profissionais, ao pensar o acolhimento dirigido aos envolvidos no processo de adoção que vivenciam esse período delicado de construção de vínculo com o filho adotivo.

\section{Metodologia}

Este artigo é um estudo teórico. Esse tipo de produção objetiva discutir teoricamente a temática, sem necessariamente ser uma revisão sistemática da literatura. Especificamente aqui tem-se como objetivo discutir o estágio de convivência, abordando o que seria a filiação adotiva e as principais dificuldades para o período do estágio de convivência a partir de uma visão ancorada na fenomenologia de Heidegger. Este filósofo discutiu uma Ontologia do Ser, ou seja, um resgate do ser e suas relações, e seus constructos podem contribuir diretamente para a temática do estágio de convivência, a partir da discussão da adoção enquanto construção de relação e sentidos. Ressalta-se que relação, aqui, não tem a conotação de duas subjetividades distintas que se encontram, mas, no conceito heideggeriano, denota horizontes que são permeados por vários aspectos, como a temporalidade e historicidade de cada ser em determinado espaço e tempo que se encontram (Feijoo, 2014).

Buscou-se na literatura estudos que pudessem compor essa discussão. Porém, como se encontrou poucas produções, apresentamos também uma breve síntese quantitativa dos artigos encontrados, pois entendemos ser importante dimensionar como a temática vem sendo discutida. Foram feitas buscas nas bases de dados: Portal Capes; Biblioteca Digital de Teses e Dissertações (BDTD); e BVSPsi; durante os meses de Abril a Julho de 2016. Não houve delimitação acerca do ano de publicação como critério de exclusão. O critério de inclusão era que as produções mencionassem ou aprofundassem o tema do estágio de convivência e vinculação adotiva. Por ser um estudo de base fenomenológica, buscou-se, ainda, produções que discutiam a temática à luz da fenomenologia, desconsiderando artigos que mencionavam adoção, mas não a temática do estágio de convivência.

Nesse levantamento foram utilizadas palavras- chave: Estágio de Convivência; Filiação Adotiva; Adoção e Fenomenologia; Filiação Adotiva e Fenomenologia; Filiação Adotiva e Cuidado; Estágio de Convivência e Fenomenologia. Percebeu-se que há poucas produções sobre a discussão do estágio de convivência. Este, quando trazido, na maioria das vezes é apontado apenas pelo aspecto legal de sua obrigatoriedade, havendo mais produções discutindo filiação adotiva em si. Ao todo, entre artigos, dissertações e teses, apenas 15 se relacionam com a temática do estágio de convivência/filiação adotiva. Tal quantitativo demonstra a pequena produção e pouca reflexão sobre o tema dentro da academia. Do total analisado, foram encontrados cinco artigos, oito dissertações e duas teses, variando entre os anos 2004 a 2015.

Buscou-se, também, relacionar os temas do estágio e da filiação com a fenomenologia, resultando em apenas dois artigos. Mesmo ampliando a consulta para o descritor adoção, encontrou-se apenas 38 produções que discutem adoção sob o olhar fenomenológico, sendo tais temática amplamente discutidas pela psicanálise, apontando para a baixa inserção da fenomenologia nos temas que envolvem contextos jurídicos.

\section{Resultados \\ A Filiação Adotiva}

O processo de adoção comumente é visto a partir da ótica de que os candidatos adotam uma criança. Mas, por entendermos que é um período que envolve a adaptação de todos os envolvidos nessa dinâmica, a criança também adota os candidatos (Dantas, 2009). Então, é preciso pensar no significado de adoção.

Antes, ressalta-se que, aqui, discutimos a adoção legal, prevista em lei, e não outras modalidades, como adoção à brasileira (quando os pais adotivos, ao receberem uma criança, a registram no cartório como se fossem os pais biológicos) ou adoção direta (quando a criança é entregue pela família biológica diretamente à adotiva, que posteriormente busca legalizar a situação junto à VIJ).

A adoção, ainda que envolva um processo e decisão judicial, é também um ato deliberadamente sentimental. Ou seja, além das etapas jurídicas pelas quais os pretendentes devem passar, é preciso também que haja uma disponibilidade afetiva para tal. "É um ato jurídico pelo qual o vínculo de filiação é criado artificialmente. (...) É uma nova forma de constituir uma família, saindo do tradicional e oportunizando a possibilidade de exercitar a maternidade/ paternidade afetivas" (Souza \& Casanova, 2011, p. 13). Do ponto de vista da família adotiva, é uma forma para exercer a parentalidade, e do ponto de vista da criança é uma alternativa ao acolhimento institucional, garantindo o direito de convivência familiar. Para ambos os lados, é uma forma de acolher e ser acolhido. 
Ainda assim, culturalmente a adoção está ligada principalmente à infertilidade, ou dificuldades em ter filhos biológicos, especialmente no Brasil (Maux \& Dutra, 2010; Weber, 2005). E esse fator, aliado à história da adoção em nível nacional e internacional, contribui para o estigma e preconceitos que a perpassam e que a colocam como filiação de segunda categoria, gerando dúvidas e ansiedades durante a decisão de se adotar (Maux \& Dutra, 2010; Weber, 2005).

Desde a ideia mais inicial sobre a possibilidade em se adotar e sua concretização de fato, judicialmente, pode haver algum tempo. E esse lapso é importante para que as decisões sejam tomadas de forma amadurecida. Mas, ao mesmo tempo, pode gerar ansiedade e medos, que também precisam ser discutidos e trabalhados. É comum que, durante esse processo, alguns questionamentos perpassem a experiência de pretendentes e crianças: (a) os pretendentes questionem sua capacidade em serem pais; (b) temam que seus filhos não os amem; (c) temam que a família biológica reapareça; (d) que a criança tenha vivido muitos eventos traumáticos e que seja difícil, tanto para ela quanto para os pretendentes, lidar com essa história pregressa; ou, (e) que a genética fale mais alto e determine o comportamento dos filhos adotivos (Souza \& Casanova, 2011). Tudo isso está ligado à cultura histórica da filiação adotiva.

A adoção sempre existiu. Os primeiros registros apontam para uma prática presente desde a Antiguidade. Com o decorrer dos tempos, as mudanças sociais ocorridas influenciaram a forma como acontecia, assumindo diferentes contornos e motivações. Especificamente no Brasil, as mudanças conduziram à cultura que se tem atualmente, de que é melhor adotar meninas, brancas e de pouca idade, especificamente saudáveis (Costa \& RossetiFerreira, 2007; Dantas, 2009; Maux \& Dutra, 2010), contribuindo diretamente para os mitos e preconceitos que cercam a adoção. Tal perfil não condiz com o quadro daquelas que podem ser adotadas no Brasil, que em sua maioria são maiores de dois anos, meninos e de pele parda (Dantas, 2009).

De acordo com dados do Conselho Nacional de Justiça (CNJ, 2019) ${ }^{2}$, no Brasil, o perfil nacional das crianças que se encontram aptas a serem adotadas é destoante do requerido pelos pretendentes à adoção. O cenário aponta o maior número de requerentes para crianças de até cinco anos, sendo 11,63\% com preferência para até um ano; 16,86\% para até dois anos; 18,35\% até três anos; 15,04\% para quatro anos; e $14,98 \%$ para até cinco anos. Após essa idade, o percentual cai vertiginosamente, chegando a $0,71 \%$ para até 12 anos e $0,16 \%$ para 16 anos. Porém, apenas 5,19\% das crianças possuem até um ano; 5,07\% têm até dois anos, $4,88 \%$ até três anos, 4,17\% até quatro

\footnotetext{
${ }^{2}$ Dados obtidos em fevereiro de 2019. Destaca-se que, dentre os adolescentes aptos a serem adotados, à época, não havia acima de 15 anos.
}

anos e $4,18 \%$ até cinco anos. Os números sobem chegando a 6,23\% para crianças de até 12 anos e $7,66 \%$ até 15 anos.

Quanto ao sexo, 26,9\% dos pretendentes aceitam apenas meninas, enquanto 8,35\% desejam somente meninos, e $64,75 \%$ dos pretendentes são indiferentes ao gênero. Porém, a maioria das crianças são meninos, representando 53,75\%, enquanto as meninas compõem 46,25\%. Sobre a etnia, 92,43\% dos pretendentes querem crianças brancas, enquanto esse número cai para 55,8\% para crianças negras, 57,97\% para amarelas, 82,73\% para pardas e $54,29 \%$ para crianças indígenas. Destacase, contudo, que $15,13 \%$ somente aceitam crianças brancas, 0,79\% aceitam apenas crianças negras, 0,09\% exclusivamente amarelas, 4,06\% somente para pardas e 0,06\% apenas indígenas. Em contraposição, $32,82 \%$ das crianças são brancas, $16,62 \%$ são negras, 0,19\% são amarelas, 49,95\% são pardas e 0,32\% são indígenas. A partir desses dados estatísticos, percebe-se que dentre esses fatores de etnia, sexo e idade, este último se mostra o que mais pesa como empecilho à adoção, ainda que haja uma grande diferença nos números entre aqueles pretendentes que aceitam somente meninas daqueles que se disponibilizam a adotar apenas meninos, bem como daqueles que preferem escolher apenas aquelas da etnia branca para as demais.

Porém, mesmo existente desde tempos remotos, a adoção inicialmente priorizava os adotantes e estava relacionada à possibilidade de dar filhos a quem não os tinha. Os filhos adotivos não tinham os mesmos direitos em relação aos filhos biológicos. Isso mudou, de forma mais embrionária com o Código de Napoleão e, principalmente, a partir da Primeira e Segunda Guerras Mundiais, quando o foco da adoção passou a se tornar a proteção integral da criança, que adquiriu legitimidade ao ser adotada e ter seus direitos enquanto filhos reconhecidos (Dantas, 2009; Pereira, 2013).

Ultimamente, essa cultura e a visão sobre adoção vêm sofrendo alteração, sendo notado pela forma como ela vem sendo retratada em novelas e filmes, como também pelas mudanças ocorridas juridicamente, pelo aumento do número de grupos de apoio à adoção e do número de adoções, inclusive de crianças maiores (Andrade, Hueb \& Alves, 2017; Maux \& Dutra, 2010; Valério \& Lyra, 2014). Mas essa cultura ainda é influenciada pela valorização do laço sanguíneo, classificado como superior ao laço adotivo, contribuindo para a visão deste como filiação inferior à biológica (Maux \& Dutra, 2010).

Ou seja, ao se optar pela adoção, os pretendentes precisam refletir e amadurecer essa decisão, pois esta filiação envolve um investimento emocional que afetará tanto as suas vidas quanto a das crianças que possivelmente possam vir a se tornar seus filhos, além de uma adaptação de ambos os lados, e de membros familiares, à nova rotina e configuração 
familiar. Logo, envolve uma preparação, da mesma forma como a gestação biológica que também gera mudanças na rotina e adaptação aos novos papeis e membros familiares (Morelli, Scorsolini-Comin \& Santeiro, 2015).

A diferença basilar entre os dois tipos de parentalidade se dá na forma como acontecem. Ser pai e mãe adotivo envolve o exercício da paternagem e maternagem, termos que estão ligadas aos cuidados desprendidos ao filho, relacionados à natureza social do ato e não à ligação biológica entre cuidador e ente cuidado. A parentalidade biológica - maternidade e a paternidade - diz respeito à procriação. Sendo assim, entende-se que todos que queiram podem exercer a maternagem/paternagem sem, necessariamente, ter gerado biologicamente aquele que é alvo de seus cuidados (Dantas, 2009; Peretto \& Valente, 2013). A noção de maternagem e paternagem ajuda a entender filiação como relacional e não biológica.

Mas, então, pensando que toda filiação se relaciona com a paternagem e maternagem, como poderíamos defini-la? O que, de fato, seria essa filiação adotiva?

No Dicionário Aurélio (Ferreira, 2010), a palavra filiação significa ato ou efeito de filiar; adoção (por filho); designação dos pais de alguém; admissão em comunidade ou instituição; descendência direta; derivação, procedência; conexão. Frisa-se o significado relacionado tanto à parentalidade biológica quanto à adotiva.

Toda constituição familiar é, portanto, filiação e uma adoção, pois, ao se inserir um novo membro na família, seja por vínculo biológico ou adotivo, deve-se investir afetiva e emocionalmente nesse novo ser que chega, despertando nele e nos familiares o sentimento de pertença (Speck, 2013), fazendo com que se estreitem os vínculos entre os envolvidos (Pinto, 2010). Em casos de adoção, essa filiação e transmissão dos valores familiares é feito apenas a partir do vínculo afetivo.

\section{A importância do Estágio de Convivência sob a ótica da Fenomenologia}

Pensando a filiação adotiva como o processo de construção de vínculos entre os membros da família, entende-se que em casos de adoção, isso se inicia no período do estágio de convivência. E, juridicamente, a obrigatoriedade desse período não possui o intuito de afirmar quem deve ser pai/ mãe. Mas, considerando que as crianças acolhidas institucionalmente estão sendo tuteladas pelo Estado, esse tem o dever de garantir que o possível novo lar lhes garanta um bom desenvolvimento. Nesse sentido, o acompanhamento é importante para assegurar que os direitos das crianças sejam respeitados, dando suporte necessário aos envolvidos nesse momento, especialmente nos casos de adoção tardia, por entender que as crianças maiores já possuem um tempo de institucionalização e maiores vivências pregressas com suas famílias de origem (Bicca \& Grzybowski, 2014).

A partir da inserção da criança nesse novo lar, na convivência com os adotantes, algumas situações são comuns e podem interferir, positivamente ou não, nessa filiação e na construção do vínculo afetivo. Abordaremos algumas dessas situações, que a literatura destaca como recorrentes. Mas entendemos que nem sempre elas ocorrem, ou na ordem aqui disposta, e que outras podem surgir. Também consideramos relevante destacar que nossa discussão se embasa numa visão fenomenológica heideggeriana, que rompe com dicotomias, subjetivismos, etapas ou fases (Feijoo, 2014). Assim, a proposta é refletir sobre aspectos frequentes durante o estágio de convivência, mas sem considerar qualquer predeterminação ou generalizações.

Primeiramente, é comum que os candidatos a pais tentem agradar a todo custo a criança recém-chegada. E isso se relaciona à tentativa em desempenharem a parentalidade perfeitamente (Campos, 2010). "Os adotantes sentem que têm de provar sua capacidade para o exercício do papel de pai e mãe, antes mesmo da concretização da adoção" (Campos, 2010, p. 6). Eles desejaram e planejaram, provavelmente por algum tempo, a chegada dessa criança. Quando isso acontece, eles acreditam que precisam ser perfeitos, para suprir qualquer necessidade que o filho possa ter e tudo que ela pode ter sido privada anteriormente.

É preciso, assim, calma, pois, mesmo que a ansiedade seja uma característica presente em praticamente todos os adotantes, é importante que ela não seja exorbitante a ponto de deixá-los tão ávidos em se apoderar desse papel que acabem se fechando numa fantasia de perfeição, que não poderá ser alcançada, culminando no insucesso da adoção. "Não é um deixar-se tragar, mas um arrancar e puxar para si” (Heidegger, 1987/2009, p. 212) e nesse apropriar-se é que se reflete sobre a experiência, mostrando aí a importância do acompanhamento do estágio de convivência e de se discutir com os todos os envolvidos sobre esse momento.

Pensando esse esforço dos candidatos a pais em uma perspectiva fenomenológica heideggeriana, é possível compreender que, na tentativa de agradar, eles podem agir sob o modo do cuidado substitutivo. Heidegger (1927/2013) nos coloca que o modo de ser do homem é o Dasein. Essa estrutura ontológica se desvela em sua própria existência, e tem como características fundamentais a abertura para o seu existir e o fato de ser ser-no-mundo (Sá, 2002). Ou seja, o Dasein não é aprioristicamente determinado, suas possibilidades para ser se desvelam e se transformam no desenrolar de sua própria existência, em relação consigo, com os outros e com o mundo que o circunda. E nessa trama de relações, lança-se mão de um modo de ser originário e ontológico da estrutura do Dasein, mas que também é ôntico no 
desdobrar da sua existência fática, que é o cuidado (Heidegger, 1927/2013).

Heidegger (1927/2013) apresenta as formas nas quais esse cuidado pode se dar, que são a ocupação e preocupação. O modo fundamental da ocupação se dá na relação com os demais entes intramundanos que são previamente dados e com os quais nos relacionamos através da utilidade instrumental; enquanto a preocupação se dá nas relações com os entes que possuem o modo de ser do Dasein (Sá, 2002), ou seja, com outros seres humanos. Como no estágio de convivência as relações estabelecidas são entre pessoas, ou seja, entre entes que possuem mundo e abertura de possibilidades, nos deteremos a este cuidado definido como preocupação.

A preocupação se apresenta em toda forma de nos relacionarmos com outras pessoas. E, em meio às diversas possibilidades de cuidarmos do outro, há duas maneiras extremas: a preocupação substitutiva e a preocupação antepositiva ou libertadora. $\mathrm{Na}$ primeira, o modo do cuidado substitui o outro, tornando-se uma tutela, fazendo pelo outro e assumindo, por ele, a responsabilidade de seu próprio existir. A preocupação antepositiva se dá no sentido contrário, de libertação, de permitir que o outro se coloque e seja ativo diante de suas possibilidades de ser (Sá, 2002). Logo, o cuidado da preocupação substitutiva "retira do outro o 'cuidado', enquanto a preocupação antepositiva se volta para a "existência do outro e não a uma coisa de que se ocupa" (Heidegger, 1927/2013, p. 178179). Além disso, Heidegger (1927/2013) destaca também a indiferença como o modo de cuidado característico da convivência cotidiana e mediana da preocupação, onde o ser tocado pelo outro com o qual convive, não se interessa. A preocupação substitutiva e antepositiva, então, são modos não indiferentes de nos relacionarmos com os outros (Sá, 2002).

Sendo assim, na tentativa de agradar, no período inicial de filiação que se inicia no estágio de convivência, os adotantes podem não permitir que a criança seja ela mesma dentro daquele espaço, restringindo suas possibilidades de ser e, até mesmo, de construir a filiação e de se relacionar. Assim, os adotantes podem fazer com que o infante se sinta sufocado em sua existência, sem espaço para ser e existir por ela mesma.

Ligado a esse cuidado substitutivo ofertado às crianças, há também a maneira como elas se comportam ao chegar ao novo lar. É frequente que elas apresentem um comportamento regressivo (Campos, 2010). Isso também pode indicar uma tentativa das crianças em reviver etapas comuns à infância que elas podem ter sido privadas, ou pode ser uma forma de ressignificar tais etapas (Alvarenga \& Bittencourt, 2013; Silva \& Benetti, 2015). Assim, elas respondem ao cuidado substitutivo como forma de agradar aos pais adotivos e de garantir a continuidade do afeto recebido.

Ou é possível, também, que elas testem esses novos pais, como forma de avaliar a disposição deles em adotá-las, o que está ligado ao medo das crianças em serem devolvidas à instituição de acolhimento (Silva \& Benetti, 2015). Em ambas as situações, podese compreender que as crianças estariam agindo de maneira inautêntica ou imprópria. Heidegger (1981) coloca que, no cotidiano, o ser humano acaba sendo absorvido pelo mundo em que está inserido, ficando, então, ontologicamente perdido na mundaneidade, sendo um não-eu, estando encoberto (Heidegger, 1981).

Portanto, ao se encontrar imerso no cotidiano, pensando e agindo conforme todos, o ser humano se comporta de forma inautêntica, alheio as suas escolhas e possibilidades mais próprias de existir. Ao testar ou regredir, e ao cuidar substitutivamente, tanto pretendentes quanto crianças, estão agindo de maneira a não permitir que o outro seja em sua propriedade. Entende-se que tais comportamentos estejam ligados às fases comuns à adoção conhecidos como fase da lua de mel (período inicial caracterizado pela vontade de agradar e, por vezes, comportamentos regressivos) e fase da lua de fel (período posterior, no qual surgem testes e expressões de agressividade) (Silva \& Benetti, 2015), mas é preciso transpor tais comportamentos para que a filiação se dê de maneira própria, onde cada membro da família possa se expressar, sem precisar agradar, testar ou temer ser quem de fato eles são.

Nesse sentido, tanto na fase da lua de mel quanto na lua de fel é imprescindível que haja espaço para conversar, possibilitando a expressão de inseguranças, medos, agressividades e afetos, permitindo, então, que se construa uma relação autêntica entre os integrantes dessa nova família. A presença da equipe técnica da VIJ é importante ao ofertar esse suporte e espaço de expressão. O acompanhamento feito por tais profissionais permite que expectativas e frustrações sejam elaboradas (Alvarenga \& Bittencourt, 2013). Com isso, geramse maiores esclarecimentos, desmistificação de estereótipos, favorecendo-se a concretização do processo, ou que se verifique a necessidade da não continuidade da adoção (Pereira, 2013).

Ressalta-se que os modos autênticos e inautênticos, bem como o cuidado antepositivo e o substitutivo, são possibilidades de expressão da existência do Dasein (Heidegger, 1927/2013), não havendo valoração entre eles, mas um entendimento de que todos se alternam e se mostram no desenrolar da trama do existir. Comportamentos que denotem um cuidado substitutivo podem se mostrar relevantes nos momentos iniciais de construção do vínculo afetivo, garantindo que a criança se permita ser protegida e cuidada, por exemplo. Mas refletimos que se faz necessário possibilitar, aos pais e aos filhos, espaços de reflexão para que não permaneçam 
na inautenticidade (forma cotidiana de existirmos) constantemente nessa relação, e que seja possível que momentos de desvelamento da autenticidade possam acontecer, onde cada um possa empunhar seu próprio projeto existencial.

Outro aspecto bastante comum em casos de adoção diz respeito à história pregressa da criança e o quanto ela pode influenciar a vida do filho (Viana, 2009). Esse temor de que a história pregressa é determinante para quem o filho virá a ser está ligada à cultura do laço de sangue que permeia nossa sociedade, discutida anteriormente. E, com peso do vínculo biológico, há o medo de que este possa interferir na vinculação adotiva e a ideia errônea de que não se deve conversar com a criança sobre seu passado.

Primeiramente, é preciso entender que, ainda que o filho receba uma carga genética, a inserção em uma nova família lhe trará novas experiências, que são fortes o suficiente para agir na construção individual (Souza \& Casanova, 2011). Sobre isso, Heidegger (1987/2009) aponta que o homem não é um ser determinado, como as ciências naturais precisam. Pelo contrário, uma característica fundamental do Dasein é justamente a sua abertura para a sua própria existência, longe de qualquer relação de causa-efeito. "O determinismo nega a liberdade” (Heidegger, 1987/2009, p. 256).

Logo, do ponto de vista fenomenológico, o peso do fator genético e o receio de que a história pregressa da criança influencie direta e negativamente em seu desenvolvimento não faz sentido. Mesmo que a fenomenologia considere a historicidade de todos os seres, em Heidegger, o caráter da abertura diz sobre a indeterminação apriorística do Dasein e sobre a liberdade na qual todos se encontram diante das possibilidades de sua existência. $\mathrm{Ou}$ seja, a historicidade e a herança genética não são os únicos fatores que influenciarão o existir. "A hereditariedade poderá surpreender (...) tanto no filho adotivo como no biológico. É imprevisível (...)" (Souza \& Casanova, 2011), demonstrando, o quanto somos, de fato, indeterminados e dificilmente previsíveis. E novos vínculos afetivos podem ser formados, independente da história pregressa da criança (Pereira, 2013).

Além disso, em alguns casos, os adotantes têm dificuldade de conversar com a criança sobre sua história, por temer despertar seu interesse em detrimento dos pais adotivos e que o filho queira conhecer mais profundamente suas histórias ou a família de origem (Pinto, 2010; Souza \& Casanova, 2011). Esses medos podem dificultar as relações entre os membros da família (Costa \& RossetiFerreira, 2007; Pinto, 2010).

Além de ser um direito da criança, conhecer sua história é organizador, do ponto de vista psicológico (Souza \& Casanova, 2011). E os requerentes são os guardióes desse enredo. Para tal, eles precisam receber informações sobre o passado e processo de institucionalização da criança (Costa \& RossetiFerreira, 2007). E é importante que eles conversem com a criança sobre tais aspectos, fazendo com que a adoção não se torne um tabu dentro da própria família. Portanto, é necessário que eles ofertem espaços de diálogos, para que a criança "preencha lacunas de tempo ou de situações não compreendidas, com o auxílio de pessoas significativas para ela e afetivamente envolvidas em seu bem-estar" (Costa \& Rosseti-Ferreira, 2007, p. 433).

Conversar com a criança sobre sua história, e não temê-la, é uma forma de fazer com que, nessa relação, não haja ocultações, permitindo que as verdades sejam desveladas e compreensões surjam, e, então, a vinculação, e o desenrolar dessas relações, sejam verdadeiras e autênticas, dando espaço para os laços afetivos. Novamente, a presença da equipe técnica nesse momento é imprescindível, discutindo, acolhendo os receios e auxiliando na ressignificação dessa história, seja para a criança, seja para os pretendentes, de maneira que a origem do filho não se torne um empecilho na relação que eles estão criando.

À medida que os vínculos vão sendo construídos, comportamentos de testes ou a necessidade de agradar (de ambas as partes), bem como alguns receios e fantasias, podem ser revistos e ressignificados, especialmente com o acompanhamento e suporte profissional. Heidegger (1954/2012, p. 125) afirma que "só é possível habitar o que se constrói”. Para o filósofo, os dois termos são inseparáveis, pois construir "significa cuidar do crescimento (...), proteger e cultivar" (Heidegger, 1954/2012, p. 127) e o habitar seria "trazer à paz de um abrigo" (Heidegger, 1954/2012, p. 129).

Logo, habitamos os espaços em que podemos nos demorar, e com isso, construímos ali um abrigo. E esse espaço não necessariamente é apenas físico, mas se estende e se amplia ao lugar e às pessoas onde encontramos morada. Podemos pensar que, no processo de filiação adotiva, que se inicia no estágio de convivência, na medida em que cada membro dessa nova família habita o seu novo papel (de pai, mãe e filho) e esse espaço, emerge daí a construção de um abrigo e a construção de novas relações.

\section{Considerações Finais}

A partir do que foi exposto, pode-se pensar que a adoção é permeada por tabus, fantasias e medos. A disposição afetiva para adotar se inicia anteriormente à própria filiação, mas a construção concreta desses novos papéis de pai/mãe e filho começa com a chegada da criança ao lar dos adotantes. Nesse período se inicia o estágio de convivência. É um momento delicado, por envolver pessoas que até então se desconheciam, podendo haver ansiedade pela construção do vínculo.

É um momento que necessita de um olhar 
atencioso para que se cuide dessa filiação, que do ponto de vista jurídico ocorre em um tempo diferente do psicológico da real construção desses papéis e relacionamentos (Silva \& Benetti, 2015). Entendemos que a filiação independe de vínculo biológico, pois tornar-se pai e mãe relaciona-se com maternagem e paternagem e não com paternidade e maternidade (Maux \& Dutra, 2010).

Sobre o estágio de convivência, ressaltamos alguns aspectos comuns em casos de adoção. Primeiramente, a necessidade dos possíveis pais em agradar a criança recém-chegada ao lar, que, a partir da cobrança que eles se fazem em serem perfeitos e com a fantasia de suprir qualquer vivência ruim que a criança possa ter tido, acabam por exercer um cuidado substitutivo, não permitindo que a criança haja por ela mesma. Já as crianças muitas vezes respondem a esse cuidado, na tentativa de agradálos através de comportamentos regressivos, ou agem de maneira a testar os limites. Assim, ambos passam a agir inautenticamente, fechando-se para outras possibilidades do se relacionar.

Outro aspecto salutar é a história pregressa da criança e o quanto ela pode influenciar negativamente na vinculação e no futuro do adotado, a partir das fantasias criadas pelos pais sobre essa trama (Bicca \& Grzybowski, 2014). Isso se dá pelo peso da cultura de laços de sangue, que se faz presente no imaginário dos adotantes, e que desconsidera a indeterminação do Dasein (Heidegger, 1927/2013).

A história pregressa também envolve o período de acolhimento institucional da criança, já que a institucionalização possui características que podem afetá-la, positiva ou negativamente (Oliveira \& Schwartz, 2013), e que também compõe a sua historicidade. Assim, tanto os adotantes quanto os adotados podem revisitar essa fase. E é preciso que os adotantes compreendam e se apropriem disso, permitindo espaços de diálogo, por serem figuras de referência afetiva para o filho. E, desta forma, mostrarão à criança que ela pode aceitar e reconhecer seu passado, sem gerar nela um possível conflito entre ser leal à filiação biológica ou à adotiva (Combier \& Binkowski, 2017).

À medida que a filiação transcorre, percebese que todos os membros dessas novas relações passam a habitá-las, no sentido heideggeriano de demorar-se, encontrar abrigo e construir vinculações possivelmente mais autênticas. Portanto, dando espaço a outras formas de cuidar que não apenas o cuidado substitutivo, ainda que este seja possível e ocorra também no cotidiano. Ainda, o que seria vínculo em uma noção heideggeriana? O Dasein é constitutivamente ser-no-mundo, sendo o mundo copresença, tudo que nos vêm ao encontro (Heidegger, 1927/2013). Estabelecemos relações, criando diferentes sentidos com as co-presenças. Vínculo seria essa construção, um debruçar-se sobre, sendo possível por compartilharmos nosso mundo e forma de existir com outros.

Ressalta-se a importância do acompanhamento desse período pela equipe técnica das VIJ, pois é um momento em que se pode propiciar escuta, acolhimento e compreensão dos anseios, dúvidas e angústias compartilhados. E a justiça, na figura da equipe técnica, não deve estar presente na vida das pessoas como julgadora, fria e imparcial, mas visando assegurar a garantia de direitos.

No estágio de convivência, permite-se que se desvelem os sentidos que os adotantes estão dando à adoção. Se pensado dessa forma, não é apenas uma avaliação, mas um momento no qual a equipe técnica pode cuidar dos adotantes e adotados, promovendo reflexões sobre a construção dessas relações, descontruindo mitos, podendo gerar maior apropriação dessa experiência, e investindo na capacidade das pessoas envolvidas em habitar essa nova configuração familiar que está se construindo. Entende-se que, com isso, a concretização da adoção pode se tornar uma possibilidade mais concreta. Em contraposição, permite também, em casos em que não seja possível a adoção, que isso seja percebido tanto pela equipe técnica quanto pelos envolvidos, não sendo unicamente uma decisão dos profissionais, mas também uma elaboração dos adotantes e da criança.

Assim, esse artigo teve intuito de discorrer brevemente sobre esse tema, pensando-o sob constructos fenomenológicos heideggerianos, sendo um passo para se pensar questões jurídicas a partir dessa teoria.

\section{Referências}

Alvarenga, L.L. \& Bittencourt, M.I.G.F. (2013). A delicada construção de um vínculo de filiação: o papel do psicólogo em processo de adoção. Pensando Famílias, 17(1), 4153. Recuperado em abril de 2016, de http:// pepsic.bvsalud.org/scielo.php?script=sci arttext\&pi$\underline{\mathrm{d}=\mathrm{S} 1679-494 \mathrm{X} 2013000100005 \& \operatorname{lng}=\mathrm{pt} \& \mathrm{t} \operatorname{lng}=\mathrm{pt}}$

Andrade, L.C., Hueb, M.F.D. \& Alves, C.M.P. (2017). Era uma vez... um estudo de caso sobre histórias e estórias adotivas. Estudos de Psicologia (Campinas), 34(1), 173-183. Recuperado em julho de 2017, de http://www.scielo.br/scielo.php?script=sci arttext\&pi$\mathrm{d}=\mathrm{S} 0103-166 \mathrm{X} 2017000100173 \& \operatorname{lng}=\mathrm{en} \& \mathrm{nrm}=$ iso

Bicca, A. \& Grzybowski, L.S. (2014). Adoção tardia: percepções dos adotantes em relação aos períodos iniciais de adaptação. Contextos Clínicos, 7(2), 155-167. Recuperado em julho de 2017, de http://pepsic.bvsalud.org/scielo.php?script=sci arttext\&pid=S1983-34822014000200005

Campos, N.M.V. (2010). Adoção tardia - característi- 
cas do estágio de convivência. Tribunal de Justiça do Distrito Federal e dos Territórios. Recuperado em abril de 2016, de http://www.tjdft.jus. br/cidadaos/infancia-e-juventude/textos-e-artigos/ adocao-tardia/view Acesso em 20/04/2017.

Combier, C.V. \& Binkowski, G. (2017). Adoção e Mito: os destinos do "mito familiar" na cena da família contemporânea: estudo a partir de um caso clínico de adoção na França atual. Àgora, 20(1), 159172. Recuperado em novembro de 2017 de http:// www.scielo.br/scielo.php?script=sci arttext\&pi$\underline{\mathrm{d}=\mathrm{S} 1516-14982017000100159 \& \text { lang }=\mathrm{pt}}$

Congresso Nacional (Brasil) (1990). Estatuto da Criança e do Adolescente, de 13 de julho de 1990. Brasília, DF: Senado Federal. Recuperado em abril de 2016, de http://www.planalto.gov.br/ ccivil 03/leis/18069.htm

Congresso Nacional (Brasil) (2009). Lei 12.010, de 3 de agosto de 2009. Brasília, DF: Senado Federal. Recuperado em abril de 2016, de http://www. planalto.gov.br/ccivil 03/ ato2007-2010/2009/lei/ $\underline{112010 . h t m}$

Conselho Nacional de Justiça (2019). Relatórios Estatísticos do Cadastro Nacional de Adoção (CNA). Recuperado em fereveiro de 2019, de http://www.cnj.jus. br/cnanovo/pages/publico/index.jsf

Costa, N.R.A. \& Rosseti-Ferreira, M.C. (2007). Tornar-se pai e mãe em um processo de adoção tardia. Psicologia: Reflexão e Crítica, 20(3), 425434. Recuperado junho de 2016, de http://www. scielo.br/pdf/prc/v20n3/a10v20n3.pdf

Dantas, F.S.S. (2009). Adoção tardia: produção de sentido acerca da maternagem, paternagem e filiação (Dissertação de Mestrado). Programa de Pós-Graduação em Psicologia, Universidade Federal de Pernambuco, Recife.

Feijoo, A.M.L.C. (2014). O horizonte histórico da contemporaneidade e a clínica psicológica existencial. In. A.M.L.C. Feijoo \& M.B.M.F. Lessa (Eds.), Fenomenologia e Práticas Clínicas. Rio de Janeiro: IFEN.

Ferreira. B. H. (2010). Dicionário Aurélio Básico da Língua Portuguesa. Rio de Janeiro, RJ: Nova Fronteira.

Heidegger, M. (1981). Todos nós... ninguém - um enfoque fenomenológico do social ( $1^{\mathrm{a}}$ ed.). São Paulo, SP: Moraes.

Heidegger, M. (2009). Seminários de Zollikon (2a ed.). Petrópolis, RJ: Vozes; Bragança Paulista, SP: Editora Universitária São Francisco. (Texto original publicado em 1987).

Heidegger, M. (2012). Ensaios e Conferências $\left(8^{\mathrm{a}}\right.$ ed.). Petrópolis, RJ: Vozes; Bragança Paulista: SP: Editora Universitária São Francisco. (Texto original publicado em 1954).

Heidegger, M. (2013). Ser e Tempo (8 ${ }^{\mathrm{a}}$ ed.). Petrópolis, RJ: Vozes; Bragança Paulista, SP: Editora Universitária São Francisco. (Texto original publicado em 1927).

Maux, A.A.B \& Dutra, E. (2010). A adoção no Brasil: algumas reflexões. Estudos e Pesquisas em Psicologia, 10(2), 356-372. Recuperado em abril de 2016, de http://www.revispsi.uerj.br/v10n2/artigos/ pdf/v10n2a05.pdf

Morelli, A.B.; Scorsolini-Comin, F. \& Santeiro, T.V. (2015). O "lugar" do filho adotivo na dinâmica parental: revisão integrativa de literatura. Psicol. Clín., 27(1), 175-194. Recuperado em abril de 2016, de http://www. scielo.br/scielo.php?script $=$ sci $\operatorname{arttext\& pi-}$ $\mathrm{d}=\mathrm{S} 0103-56652015000100175 \&$ lang=pt

Oliveira, D.S. \& Schwartz, E.D.R. (2013). The new adoption law: legal and psychological aspects. Estud. Psicol. (Campinas), 30(3), 445-453. Recuperado em abril de 2016, de http://www. scielo.br/scielo.php?script=sci arttext\&pi$\mathrm{d}=\mathrm{S} 0103-166 \times 2013000300014 \& \operatorname{lng}=$ en \&nrm=iso

Pereira, E.L. (2013). Adoção Internacional: realidades, conceitos e preconceitos. Emancipação, 13(3), 47-66. Recuperado abril de 2016, de http://www. revistas2.uepg.br/index.php/emancipacao/article/ view/4516/4372

Peretto, K. I. M. \& Valente, M. L. L. C. (2013). Pensando a adoção olhando a maternagem. Colloquim Humanarum, 10(1), 70-96. Recuperado em maio de 2016, de http://revistas.unoeste.br/ revistas/ojs/index.php/ch/article/viewFile/514/1056

Pinto, L.M.S. (2010). Reflexões sobre o processo de vínculo na filiação adotiva (Dissertação de Mestrado). Programa de Pós-Graduação em Psicologia Clínica, Universidade Católica de Pernambuco, Recife.

Sá, R. N. (2002). A noção heideggeriana de cuidado (Sorge) e a clínica psicoterápica. Rev. de Filosofia Veritas, 45(2), 259-266.

Segalin, A. (2013). Serviço social e viabilização de direitos: a licença/salário-maternidade nos casos de adoção. Serviço Social e Sociedade, 115, 581-594. Recuperado em julho de 2016, de http://www.scielo.br/scielo.php?script=sci_arttext\&pi$\mathrm{d}=$ S0101-66282013000300010\&lng=en\&nrm=iso\&tlng=pt

Silva, C.L. \& Benetti, S.P.C. (2015). Older child adop- 
tion: the affiliation process. Estudos de Psicologia, 32(1), 121-127. Recuperado em maio de 2016, dehttp://www.scielo.br/scielo.php?script=sci arttext\&pid=S0103-166X2015000100121\&lang=pt

Souza, H.P. \& Casanova, R.P.S. (2011). Adoção: o amor faz o mundo girar mais rápido ( $1^{\mathrm{a}} \mathrm{ed}$.). Curitiba, PR: Juruá.

Speck, S. (2013). De um nascimento a outro: o processo de filiação numa adoção de crianças maiores (Dissertação de Mestrado). Programa de Pós-graduação em Psicologia Clínica, Universidade Católica de Pernambuco, Recife.

Valério, T.A.M. \& Lyra, M.C.D.P. (2014). A construção cultural de significados sobre adoção: um processo semiótico. Psicol. Soc., 26(3), 716725. Recuperado em junho de 2016, de http:// www.scielo.br/scielo.php?script=sci arttext\&pi$\underline{\mathrm{d}=\mathrm{S} 0102-71822014000300020 \& l a n g=p t}$

Viana, J.S. (2009). Construindo laços, (des)atando angústias: um estudo sobre adoção e paternidade/ maternidade em trajetórias conjugais (Dissertação de Mestrado). Programa de Pós-Graduação em Família na Sociedade Contemporânea, Universidade Católica do Salvador, Salvador.
Weber, L.N.D. (2005). Abandono, institucionalização e adoção no Brasil: problemas e soluções. O Social em Questão, 14(2), 53-70. Recuperado em abril de 2016, de http://osocialemquestao.ser. puc-rio.br/media/v14n14a05.pdf

Laura Cristina Santos Damásio de Oliveira (https:// orcid.org/0000-0001-9208-670X), Universidade Federal do Rio Grande do Norte. E-mail: laura damasio@yahoo.com.br

Ana Andréa Barbosa Maux, Centro Universitário Facex (UniFacex).
Recebido em 07.03.2019

Primeira Decisão Editorial em 28.09.2019 Segunda Decisão Editorial em 12.01.2021

Aceito em 17.04.2021 